\title{
Simultaneous effect of cathode potentials and magnetite concentrations on methanogenesis of acetic acid under different ammonia conditions
}

\author{
Arma Yulisa ${ }^{1}$, Joonyeob Lee ${ }^{2}$, Sang Hyeok Park ${ }^{1}$, Seokhwan Hwang ${ }^{1,3^{\dagger}}$ \\ ${ }^{1}$ Division of Environmental Science and Engineering, Pohang University of Science and Technology (POSTECH), Gyeongbuk 37673, Republic of Korea \\ ${ }^{2}$ Department of Environmental Engineering, Pukyong National University, Busan 48513, Republic of Korea \\ ${ }^{3}$ Institute for Convergence Research and Education in Advanced Technology (I-CREATE), Yonsei University, Incheon 21983, Republic of Korea
}

\begin{abstract}
Electromethanogenesis (EM) is a system that facilitates direct interspecies electron transfer (DIET) in anaerobic digestion (AD) by providing an external power supply to favor desired reactions. Substrates of $\mathrm{AD}$ commonly contain ammonia $\left(\mathrm{NH}_{3}\right)$ as biodegradation product of nitrogen-rich compounds that can deteriorate the stability of $\mathrm{AD}$ process. Optimized cathode potential $\left(V_{\mathrm{CAT}}\right)$ and magnetite (Mag) concentration ([Mag]) are expected to improve $\mathrm{AD}$ efficiency in the presence of $\mathrm{NH}_{3}$. Response surface analysis with central composite face-centered design was used in this study to investigate the effect of $V_{\mathrm{CAT}}$ and [Mag] under different total ammonia nitrogen concentration ([TAN]). Highest cumulative methane production was achieved at $V_{\text {CAT }}=-737.4 \mathrm{mV}$, [Mag] $=18.2 \mathrm{mM}$, and $[\mathrm{TAN}]=1.5 \mathrm{~g} / \mathrm{L}$; highest acetate degradation rate was achieved at $V_{\text {CAT }}$ $=757.6 \mathrm{mV}$, $[\mathrm{Mag}]=21.4 \mathrm{mM}$, and $[\mathrm{TAN}]=1.5 \mathrm{~g} / \mathrm{L}$. The study demonstrated that $V_{\text {CAT }}$ promotes either microbial growth or electrochemical $\mathrm{NH}_{3}$ removal. A Shift from acetoclastic to hydrogenotrophic pathway was also observed by the increase of hydrogenotrophic methanogen populations at the end of experiment. This study is beneficial for process control of $\mathrm{AD}$ under different $\mathrm{NH}_{3}$ conditions.
\end{abstract}

Keywords: Ammonia, Anaerobic digestion, Central composite face-centered, Electromethanogenesis, Magnetite

\section{Introduction}

Anaerobic digestion $(\mathrm{AD})$ is an organic-waste treatment method that generates energy source methane $\left(\mathrm{CH}_{4}\right)$. $\mathrm{AD}$ commonly operates in mesophilic conditions and requires long degradation time (> 30 d). As a result, organic removal efficiency only reaches $40-70 \%$, and $\mathrm{CH}_{4}$ content reaches only $50-60 \% . \mathrm{AD}$ is a series of biological reactions performed by various microbial groups [1]. Electron transfer is a vital intermediate in this process; in many $\mathrm{AD}$ systems, this function is performed by hydrogen gas $\left(\mathrm{H}_{2}\right)$ that is generated by bacteria and consumed by methanogens to maintain low $\mathrm{H}_{2}$ partial pressure, but in wet- $\mathrm{AD}$, this process is limited by the slow growth rate of methanogens $[2,3]$. DIET may provide an alternative because it does not require energy allocation to multiple enzymatic steps to produce $\mathrm{H}_{2}$. Therefore, DIET increases substrate degradation rate and biogas production [3].
EM is a system that facilitates DIET in AD. EM overcomes thermodynamic constraints by providing external power supply to favor desired reaction [4]. EM operated at $300 \mathrm{mV}$ reached steady-state condition in $50 \mathrm{~d}$ and produced $\mathrm{CH}_{4}$ yield $0.34 \mathrm{~L} / \mathrm{g}-\mathrm{COD}_{\text {removed; }}$ whereas control reactor required $100 \mathrm{~d}$ to reach steady-state and produced $\mathrm{CH}_{4}$ yield $0.2 \mathrm{~L} / \mathrm{g}-\mathrm{COD}_{\text {removed }}$ [5]. In another study, EM operated at 1,000 mV achieved 2.1 times higher maximum $\mathrm{CH}_{4}$ yields than control reactor [6]. Furthermore, COD removal efficiency of EM operated at $400 \mathrm{mV}$ and 1,000 $\mathrm{mV}$ reached 100\% within $72 \mathrm{~h}$, whereas conventional $\mathrm{AD}$ only reached 56.5\% [7]. In summary, previous studies were conducted to investigate the effect of applying voltages on reactors' performance and the results showed the improvement in $\mathrm{CH}_{4}$ yield and removal efficiency.

Mag $\left(\mathrm{Fe}^{2+}\left(\mathrm{Fe}^{3+}\right)_{2}\left(\mathrm{O}^{2-}\right)_{4}\right)$ supplementation also facilitates DIET in $\mathrm{AD}$. Electron transfer rate facilitated by Mag was reported $10^{6}$ times higher than control reactors; thereby, enhanced $\mathrm{CH}_{4}$ production
This is an Open Access article distributed under the terms of the Creative Commons Attribution Non-Commercial License (http://creativecommons.org/licenses/by-nc/3.0/) which permits unrestricted non-commercial use, distribution, and reproduction in any medium, provided the original work is properly cited.

Copyright (C) 2022 Korean Society of Environmental Engineers
Received July 06, 2021 Accepted November 24, 2021

${ }^{\dagger}$ Corresponding author

E-mail: shwang@postech.ac.kr

Tel: +82-54-279-2282 Fax: +82-54-279-8299

ORCID: 0000-0002-7545-108X 
by $33 \%$ [8]. Under $\mathrm{NH}_{3}$ stress conditions, Mag supplementation increased specific methanogenic activity $\left(R_{\mathrm{CH} 4}\right)$ of reactors fed with acetate, propionate, and butyrate by $58 \%, 20 \%$, and $15 \%$, respectively [9]. Previous studies were conducted to quantify the effect of Mag supplementation in methanogenesis, and the results showed the enhancement in $\mathrm{CH}_{4}$ production.

Adding Mag to EM system has also been proposed to improve the conductivity around electrode surfaces. Mag facilitates electron transfer from electroactive microbes located far from electrode surface because it acts as electron conduits [10]. The costs of implementing EM systems are being reduced by development of inexpensive electrode materials and efficient system configurations [4]. Also, Mag can be recycled for long-term continuous $\mathrm{AD}(\geq$ 317 d) without compensating DIET activity or methanogenesis efficiency [11].

Still, adoption of EM systems coupled with Mag supplementation requires optimization of EM conditions with Mag supplementation under various substrate conditions that the field may encounter, such as the presence of $\mathrm{NH}_{3}$. EM or $\mathrm{AD}$ system coupled with Mag supplementation has been investigated under optimal conditions $[1,4,5,7,12]$. However, protein degradation produces $\mathrm{NH}_{3}$ as a byproduct, and proteins usually comprise $40-70 \%$ of total volatile solid in $\mathrm{AD}$ substrates, so $\left[\mathrm{NH}_{3}\right]$ can build to levels that inhibit the activity of methanogenetic consortia [13, 14].

A certain amount of $\left[\mathrm{NH}_{3}\right](<200 \mathrm{mg} / \mathrm{L})$ is beneficial for microbial growth, but high $\left[\mathrm{NH}_{3}\right]$ may restrict it [13]. $\mathrm{NH}_{3}$ diffuses passively into microbial cells and thereby increases the intracellular $\mathrm{pH}$. To counteract this effect, cells must devote energy to proton balancing by using a $\mathrm{K}^{+}$pump. Therefore, it increases the maintenance energy needed to survive in high $\left[\mathrm{NH}_{3}\right]$ and potentially inhibits other enzymatic reactions involved in methanogenesis [15].

There is lack of study regarding the optimum operational condition of EM coupled with Mag supplementation under different $\mathrm{NH}_{3}$ conditions. Therefore, this study was conducted to investigate the effect of $V_{\mathrm{CAT}}$ and [Mag] under different $\mathrm{NH}_{3}$ conditions on methanogenesis of acetate. Acetate is an important intermediate that contributed to two-third of produced $\mathrm{CH}_{4}$. Considering the roles of acetate as a pivotal intermediate and methanogenic precursor consolidates its importance in $\mathrm{AD}$ [16]. This study was also conducted to investigate how independent variables affect microbial growth. This study is significant to identify conditions that are beneficial for full-scale operation of an EM system that uses Mag supplementation.

\section{Material and Methods}

\subsection{Inoculum Source and Media}

The microbial seed was collected from $3.5 \mathrm{~L}$ (working volume) continuous lab-scale mesophilic anaerobic reactors operated for two years, treating sludge and foodwaste. Throughout the operation of inoculum system, [TAN] was $<1.5 \mathrm{~g} / \mathrm{L}$ and $14.9 \mathrm{~g}-\mathrm{VSS} / \mathrm{L}$. The inoculum source had never been exposed to any bioelectrochemical systems nor supplemented with any semi(conductive) materials. Before inoculation, the seed was starved for seven days at $37^{\circ} \mathrm{C}$.
Anaerobic basal media was prepared as previously described [17]. The growth medium was supplied with 2 g-COD acetate/L as substrate. Different concentrations of ammonium chloride 2.2, 11.7, and $21.3 \mathrm{~g} / \mathrm{L}$ and $1.3 \mathrm{~g} / \mathrm{L}$ sodium bicarbonate were supplied as $\mathrm{NH}_{3}$ nitrogen and bicarbonate sources.

\subsection{Construction of EM Reactor and Operational Conditions}

Single-chamber membrane-less systems were constructed for this study and operated in batch mode. The EM reactors (Fig. 1) were composed of 320-mL glass bottles (HwaIn Auto Living Co., China) with 180-mL working volume. Electrodes were treated and prepared as previously described [18]. The anode was $3.5 \mathrm{~cm} \times 2.0 \mathrm{~cm}$ (length $\times$ width) isomolded graphite plate (Grade GM-10; GraphiteStore.com, Inc., USA). The cathode was stainless steel mesh (type 304, mesh-size 90 x 90; McMaster-Carr, USA) cut in the same dimension as anode. The reference electrode (RE) was Ag/AgCl RE-21B EC-Frontier, Japan (+210 mV vs. standard hydrogen electrode, SHE). Voltages in this manuscript were reported with respect to SHE. Electrochemical monitoring was performed by multichannel Potentiostat/Galvanostat WMPG1000LeK8 (WonATech, Korea).

The reactors were supplied with basal media containing substrate and $1 \mathrm{~g}-\mathrm{VSS} / \mathrm{L}$ inoculum source, then purged with 99.9\% nitrogen gas. The medium's $\mathrm{pH}$ was maintained at $7.5 \pm 0.1$ by adding $2.5-\mathrm{N}$ $\mathrm{NaOH}$ or $2-\mathrm{N} \mathrm{HCl}$ as required. The temperature was maintained at $37 \pm 1^{\circ} \mathrm{C}$. The reactors were operated under $120 \mathrm{rpm}$ continuous stirring. Experiments were conducted until biogas production ceased and the substrate completely degraded.

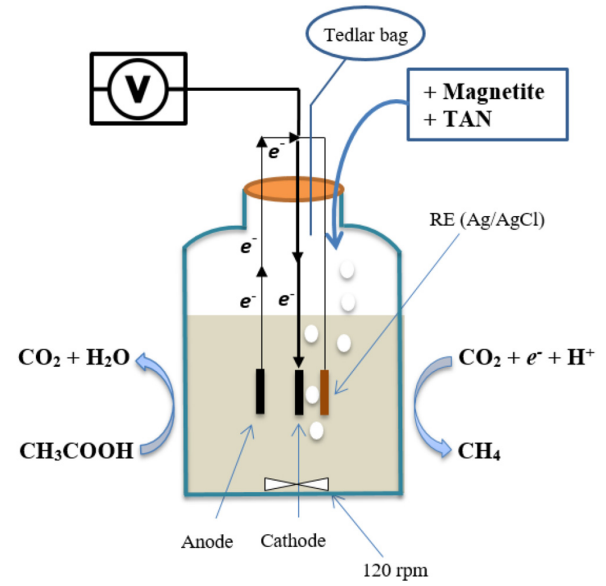

Fig. 1. Schematic diagram of electromethanogenesis system with addition of magnetite and TAN.

\subsection{Experimental Design}

A central composite design face-centered (CCF) with full $3^{3}$ factorial design was used, because the region of operability covers the region of interest. $V_{\mathrm{CAT}} X_{1}$, [Mag] $X_{2}$, and [TAN] $X_{3}$ were independent variables applied (Table 1 ), and their ranges were determined in preliminary experiment (data not shown). To evaluate the models' error, center points $(0,0,0)$ were run in triplicate. Seventeen experimental runs were conducted (Table 2). Statistical analysis of CCF was performed using Minitab 17.1.0, PA-USA. 
Table 1. Experimental Levels of Independent Variables

\begin{tabular}{lccc}
\hline \multirow{2}{*}{ Independent variable } & \multicolumn{3}{c}{ Level } \\
\cline { 2 - 4 } & $\mathbf{- 1}$ & $\mathbf{0}$ & $\mathbf{+ 1}$ \\
\hline$X_{1}:$ Cathode potential $(\mathrm{mV})$ & $-1,000$ & -800 & -600 \\
$X_{2}:[$ Magnetite] $(\mathrm{mM})$ & 0 & 20 & 40 \\
$X_{3}:[\mathrm{TAN}](\mathrm{g} / \mathrm{L})$ & 1.5 & 4.0 & 6.5 \\
\hline
\end{tabular}

The observed responses were cumulative $\mathrm{CH}_{4}$ production $Y_{1}$ and acetate degradation rate $Y_{2}$. Second-order polynomial model, Eq. (1) was used to analyze and fit experimental results obtained from CCF design [19].

$$
Y=\beta_{0}+\sum_{i=1}^{k} \beta_{i} x_{i}+\sum_{i-1}^{k} \beta_{i i} x_{i}^{2}+\sum_{1 \leq i \leq j}^{k} \beta_{i j} x_{i} x_{j}
$$

where $Y$ is predicted response; $\beta_{0}$ is constant term; $k$ represents number of variables; $\beta_{\mathrm{i}}, \beta_{\mathrm{ii}}$ and $\beta_{\mathrm{ij}}$ represent coefficient of linear, quadratic, and interaction effect; $\mathrm{x}_{\mathrm{i}}$ and $\mathrm{x}_{\mathrm{j}}$ are coded values variables $i$ and $j$.

$V_{\mathrm{CAT}}$ was selected considering over potential and electromotive force that favors $\mathrm{CH}_{4}$ production [20, 21]. Acetate as simple substrate was supplied to avoid any side reactions that may occur at $-1,000 \leq V_{\mathrm{CAT}} \leq-600 \mathrm{mV}$, which can decrease $\mathrm{CH}_{4}$ production [22]. [Mag] added to the systems was selected considering previous studies [12, 23]. [TAN] was selected considering inhibitory and non-inhibitory level: $1.5 \mathrm{~g}$-TAN/L is accepted as non-inhibitory level, thus, used as low concentration; 4 g-TAN/L that reduces methanogenesis by $40-60 \%$ was chosen as center point; and 6.5 g-TAN/L that reduces methanogenesis by $80-100 \%$ was set as maximum $[\mathrm{TAN}][13,14]$. Maximum [TAN] used in this study also adopted from maximum [TAN] observed in ten full-scale anaerobic digesters treating different types of protein-rich substrates [24].

\subsection{Real-time Quantitative Polymerase chain Reaction (qPCR) Analysis}

Samples for qPCR analysis were taken at the beginning and endpoints of experiment. Total DNAs of the samples were extracted using a fully-automated nucleic acid extractor (Magtration System 12GC, PSS-Co., Japan). $100 \mu \mathrm{L}$ Tris-HCl buffer (pH 8.0) was added for elution of the extracted DNA. The eluted DNA preserved at $-20^{\circ} \mathrm{C}$ for further analysis. TaqMan probe-primers, as previously reported [25], were used to quantify population of total bacteria and archaea, Methanosaetacea, Methanosarcinacea, Methanomicrobiales, Methanobacteriales, and Methanococcales using qPCR analyzer (LightCycler 480-Roche, Switzerland).

\subsection{Physicochemical Analysis}

Gas volume was measured using water displacement method. Biogas contents were analyzed by gas chromatograph (GC-HP 6890, Agilent, Palo Alto, CA-USA), equipped with HP-Plot Q packed column and thermal conductivity detector. Helium (He) used as carrier gas with $20 \mathrm{~mL} / \mathrm{min}$ flow rate. Acetate concentrations were analyzed using gas chromatograph (GC-HP 6890 Plus Agilent, Palo Alto, CA-USA), equipped with Innowax capillary column (Agilent) and flame ionization detector. The carrier gas was He with 10:1 split ratio and flow rate $2.5 \mathrm{~mL} / \mathrm{min}$. Standard methods protocols [26] were applied to measure [TAN] using Kjeldahl method. pH was measured using a pH electrode (Cole-Parmer Instrument). All analytical items were analyzed in triplicate, and results represented as mean \pm standard deviation.

\subsection{Statistical Analysis}

Acetate degradation rate was estimated using first-order kinetic model:

Table 2. Response Values of $3^{3}$ Central Composite Face-centered (CCF) Experimental Runs

\begin{tabular}{|c|c|c|c|c|c|c|}
\hline \multirow[b]{2}{*}{ Reactor } & \multicolumn{3}{|c|}{ Independent variable } & \multicolumn{3}{|c|}{ Dependent variable } \\
\hline & $\begin{array}{l}X_{1} \text { : Cathode potential } \\
(\mathrm{mV})\end{array}$ & $\begin{array}{c}X_{2}: \text { [Magnetite] } \\
(\mathrm{mM})\end{array}$ & $\begin{array}{c}X_{3}:[\text { TAN] } \\
(\mathrm{g} / \mathrm{L})\end{array}$ & $\begin{array}{c}Y_{1}: \text { Cumulative } \mathrm{CH}_{4} \\
\text { production }\left(\mathrm{mL}-\mathrm{CH}_{4} / \mathrm{L}\right)\end{array}$ & $\begin{array}{c}Y_{2}: \text { Acetate } \\
\text { degradation rate }\end{array}$ & $\begin{array}{c}R^{2} \text { of acetate } \\
\text { degradation rate }\end{array}$ \\
\hline $\mathrm{R}-1$ & $-1,000$ & 0 & 1.5 & 236.1 & 0.050 & 0.993 \\
\hline $\mathrm{R}-2$ & -600 & 0 & 1.5 & 587.0 & 0.092 & 0.993 \\
\hline $\mathrm{R}-3$ & $-1,000$ & 40 & 1.5 & 173.5 & 0.054 & 0.975 \\
\hline $\mathrm{R}-4$ & -600 & 40 & 1.5 & 598.8 & 0.099 & 0.987 \\
\hline R-5 & $-1,000$ & 0 & 6.5 & 150.2 & 0.035 & 0.986 \\
\hline R-6 & -600 & 0 & 6.5 & 44.7 & 0.021 & 0.993 \\
\hline $\mathrm{R}-7$ & $-1,000$ & 40 & 6.5 & 170.4 & 0.046 & 0.986 \\
\hline $\mathrm{R}-8$ & -600 & 40 & 6.5 & 67.6 & 0.029 & 0.996 \\
\hline R-9 & $-1,000$ & 20 & 4.0 & 175.1 & 0.064 & 0.978 \\
\hline $\mathrm{R}-10$ & -600 & 20 & 4.0 & 236.0 & 0.031 & 0.965 \\
\hline $\mathrm{R}-11$ & -800 & 0 & 4.0 & 450.3 & 0.074 & 0.967 \\
\hline $\mathrm{R}-12$ & -800 & 40 & 4.0 & 460.2 & 0.075 & 0.993 \\
\hline R-13 & -800 & 20 & 1.5 & 824.6 & 0.147 & 0.983 \\
\hline R-14 & -800 & 20 & 6.5 & 281.8 & 0.070 & 0.987 \\
\hline R-15a & -800 & 20 & 4.0 & 551.0 & 0.093 & 0.988 \\
\hline R-15b & -800 & 20 & 4.0 & 580.5 & 0.088 & 0.989 \\
\hline R-15c & -800 & 20 & 4.0 & 600.6 & 0.077 & 0.997 \\
\hline
\end{tabular}




$$
[\text { Acetate }]_{t}=[\text { Acetate }]_{0} \cdot e^{-k t}
$$

where $[\text { Acetate }]_{t}(\mathrm{~g}-\mathrm{COD} / \mathrm{L})$ is acetate concentration at $t$ observation time; $[\text { Acetate }]_{0}(\mathrm{~g}-\mathrm{COD} / \mathrm{L})$ is initial acetate concentration; $k\left(\mathrm{~d}^{-1}\right)$ is first-order kinetic coefficient for acetate degradation rate; and $t$ (d) is observation time. Principal component analysis (PCA), analysis of similarity (ANOSIM), and Pearson $r$ correlation were performed using statistical language R-4.0.2.

\section{Results and Discussion}

\subsection{Model Accuracy and Validation}

CCF design was used to quantify the combine effects of independent variables on methanogenesis of acetate under different $\mathrm{NH}_{3}$ conditions. The following quadratic equations illustrate the mathematical-statistical relationship between factors and responses in coded units.

$$
\begin{aligned}
Y_{1}= & -2809-10.56 X_{1}+5.55 X_{2}-336.9 X_{3}-7.38 \times 10^{-3} X_{1}^{2} \\
& -0.114 X_{2}^{2}+8.39 X_{3}^{2}+2.41 \times 10^{-3} X_{1} X_{2}-0.2461 X_{1} X_{3} \\
& +0.235 X_{2} X_{3}\left(R^{2}=0.950\right) \\
Y_{2}= & -0.383-1.493 \times 10^{-3} X_{1}+1.43 \times 10^{-3} X_{2}-0.0598 X_{3} \\
& -10^{-6} X_{1}^{2}-3.4 \times 10^{-5} X_{2}^{2}+3.27 \times 10^{-3} X_{3}^{2}-2.9 \times 10^{-5} X_{1} X_{3} \\
& +2 \times 10^{-5} X_{2} X_{3}\left(R^{2}=0.903\right)
\end{aligned}
$$

where $Y_{1}$ represents cumulative $\mathrm{CH}_{4}$ production, $Y_{2}$ represents ace- tate degradation rate, $X_{1}$ is $V_{\mathrm{CAT}}, X_{2}$ is [Mag], and $X_{3}$ is [TAN]. The coefficient of determination $R^{2}$ indicates the accuracy of polynomial equality [27]. Calculated $R^{2}=0.950$ for $Y_{1}$ and 0.903 for $Y_{2}$ denote that the models explain $95 \%$ of cumulative $\mathrm{CH}_{4}$ production and $90.3 \%$ of acetate degradation rate.

Response surface plots (Fig. 2) drawn using Eq. (3) and (4) illustrate the function of cumulative $\mathrm{CH}_{4}$ production and acetate degradation rate when [TAN] was held at center point $(4.0 \mathrm{~g} / \mathrm{L})$. The maximum value of both responses is located inside the experimental region (Fig. 2a, b). The adequacy of the models was confirmed by ANOVA results (Table 3). Both response models were significant $(p<0.05)$ and had insignificant lack of fit $(p>0.05)$ that indicates the models were fitted well to the experimental data and can be used to predict the responses [19].

Response optimizer goals were set at maximum point to determine optimal conditions of independent variables with maximum responses. A validation trial was performed to assess the models by comparing the predicted and actual values at the identified desirable conditions. The difference between predicted and actual results was $1.86 \%$ for $Y_{1}$ and $4.63 \%$ for $Y_{2}$ (Table 4 ). Up to $5 \%$ difference between predicted and actual values is acceptable to confirm the adequacy of response surface models [27].

Optimized $V_{\mathrm{CAT}}=-737.4 \mathrm{mV}$ for $Y_{1}$ and $-757.6 \mathrm{mV}$ for $Y_{2}$ are more than enough to drive reactions (Eq. (5) and (6)) on cathode

\begin{tabular}{|c|c|c|c|c|c|c|c|c|c|}
\hline \multirow{2}{*}{ Source } & \multirow{2}{*}{$d f$} & \multicolumn{4}{|c|}{$Y_{1}$ (Cumulative $\mathrm{CH}_{4}$ production $\left(\mathrm{mL}-\mathrm{CH}_{4} / \mathrm{L}\right)$ ) } & \multicolumn{4}{|c|}{$Y_{2}$ (Acetate degradation rate) } \\
\hline & & SS & MS & $\boldsymbol{F}$ & $p$ & SS & MS & $\boldsymbol{F}$ & $p$ \\
\hline Model & 9 & 813,238 & 90,360 & 14.79 & $0.001^{\mathrm{a}}$ & 0.01461 & 0.00162 & 7.45 & $0.008^{\mathrm{a}}$ \\
\hline$X_{1}$ & 1 & 39,539 & 39,539 & 6.47 & $0.038^{\mathrm{a}}$ & 0.00005 & 0.00005 & 0.24 & $0.642^{\mathrm{b}}$ \\
\hline$X_{2}$ & 1 & 0 & 0 & 0.00 & $0.993^{\mathrm{b}}$ & 0.00009 & 0.00009 & 0.43 & $0.533^{\mathrm{b}}$ \\
\hline$X_{3}$ & 1 & 290,805 & 290,805 & 47.6 & $0.000^{\mathrm{a}}$ & 0.00581 & 0.00581 & 25.95 & $0.001^{\mathrm{a}}$ \\
\hline$X_{1}^{2}$ & 1 & 233,482 & 233,482 & 38.22 & $0.000^{\mathrm{a}}$ & 0.00441 & 0.00441 & 19.70 & $0.003^{\mathrm{a}}$ \\
\hline$X_{2}^{2}$ & 1 & 5,547 & 5,547 & 0.91 & $0.372^{\mathrm{b}}$ & 0.00049 & 0.00049 & 2.20 & $0.181^{b}$ \\
\hline$X_{3}^{2}$ & 1 & 7,370 & 7,370 & 1.21 & $0.308^{\mathrm{b}}$ & 0.00111 & 0.00111 & 5.00 & $0.061^{b}$ \\
\hline$X_{1} X_{2}$ & 1 & 743 & 743 & 0.12 & $0.738^{\mathrm{b}}$ & 0.00000 & 0.00000 & 0.00 & $1.000^{\mathrm{b}}$ \\
\hline$X_{1} X_{3}$ & 1 & 121,155 & 121,155 & 19.83 & $0.003^{\mathrm{a}}$ & 0.00174 & 0.00174 & 7.78 & $0.027^{\mathrm{a}}$ \\
\hline$X_{2} X_{3}$ & 1 & 1102 & 1,102 & 0.18 & $0.684^{\mathrm{b}}$ & 0.00001 & 0.00001 & 0.04 & $0.855^{\mathrm{b}}$ \\
\hline Error & 7 & 42,767 & 6,110 & & & 0.00154 & 0.00022 & & \\
\hline Lack of fit & 5 & 41,522 & 8,304 & 13.34 & $0.071^{\mathrm{b}}$ & 0.00142 & 0.00028 & 4.72 & $0.200^{\mathrm{b}}$ \\
\hline Pure error & 2 & 1,245 & 622 & & & 0.00012 & 0.00006 & & \\
\hline Total & 16 & 856,005 & & & & 0.01624 & & & \\
\hline
\end{tabular}
surface, which at least requires $-650 \mathrm{mV}$. More negative $V_{\mathrm{CAT}}$ is required to accommodate ohmic losses [28]. The result is aligned with previous study that reported $-600 \leq V_{\mathrm{CAT}} \leq-800$ $\mathrm{mV}$ improved $\mathrm{CH}_{4}$ production and substrate degradation in $\mathrm{AD}$ systems [29].

Table 3. ANOVA of $3^{3}$ CCF Experimental Design on Two Response Functions

$d f$ : degree of freedom; $S S$ : sum of squares; $M S$ : mean square; ${ }^{a}: p$-value $<0.05 ;{ }^{\text {b }}: p$-value $\geq 0.05$

Table 4. Validation Test Results of Cumulative $\mathrm{CH}_{4}$ Production $\left(Y_{1}\right)$ an Acetate Degradation Rate $\left(Y_{2}\right)$

\begin{tabular}{lcccccc}
\hline Response & $\boldsymbol{X}_{\mathbf{1}}$ & $\boldsymbol{X}_{\mathbf{2}}$ & $\boldsymbol{X}_{\mathbf{3}}$ & Predicted & Actual & Difference (\%) \\
\hline$Y_{1}$ & -737.4 & 18.2 & 1.5 & 786.24 & 771.60 & 1.86 \\
$Y_{2}$ & -757.6 & 21.4 & 1.5 & 0.1336 & 0.1402 & 4.71 \\
\hline
\end{tabular}




$$
\begin{gathered}
\mathrm{CO}_{2}+8 \mathrm{H}^{+}+8 e^{-} \rightarrow \mathrm{CH}_{4}+\mathrm{H}_{2} \mathrm{O}, \mathrm{E}=-0.24 \mathrm{~V} \\
2 \mathrm{H}^{+}+2 e^{-} \rightarrow \mathrm{H}_{2}, \mathrm{E}=-0.41 \mathrm{~V}
\end{gathered}
$$

$V_{\text {CAT }}$ significantly affected cumulative $\mathrm{CH}_{4}$ production (Table 3), as shown in previous study [29]. In EM system, cathode acts as electron donor that is essential to control $\mathrm{CH}_{4}$ production, $\mathrm{CH}_{4}$ yield, and reaction kinetics [30]. $V_{\text {СAT }}$ also affects the availability of electrons at the cathode and ultimately also affects the expression of genes related to $\mathrm{CH}_{4}$ metabolism. For instance, the expression of methyl-coenzyme reductase (Mcr) reported $50 \%$ higher at $V_{\text {CAT }}=-1,000 \mathrm{mV}$ vs. $\mathrm{Ag} / \mathrm{AgCl}$ $\left(-800 \mathrm{mV}\right.$ vs. SHE) than at $V_{\mathrm{CAT}}=-700 \mathrm{mV}$ vs. $\mathrm{Ag} / \mathrm{AgCl}(-500 \mathrm{mV}$ vs. SHE). Mcr catalyzes the final step of $\mathrm{CO}_{2}$ reduction to $\mathrm{CH}_{4}$, so decrease in Mcr would decrease $\mathrm{CH}_{4}$ production [31]. Therefore, applying appropriate $V_{\mathrm{CAT}}$ is essential to favor EM condition. These are the reasons that $V_{\mathrm{CAT}}$ was selected as critical parameter in this study.

Optimized [Mag] was $18.2 \mathrm{mM}$ for $Y_{1}$ and $21.4 \mathrm{mM}$ for $Y_{2}$. These results confirmed the result of previous study [23] that investigated the effect of [Mag] on cumulative $\mathrm{CH}_{4}$ production and $\mathrm{CH}_{4}$ production rate until $320 \mathrm{mM}$. The authors stated that $20 \mathrm{mM}$ of Mag enhanced
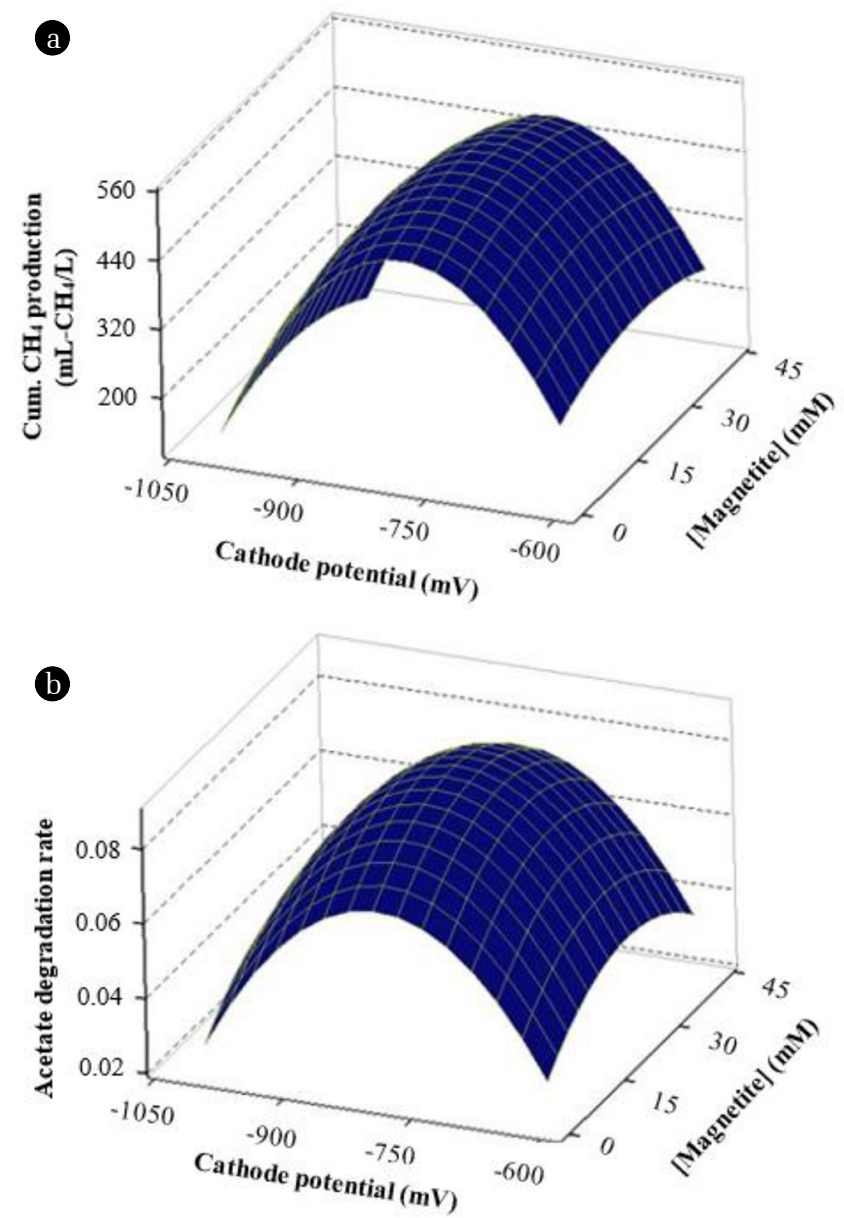

Fig. 2. Response surface as the function of cathode potential and [magnetite] when [TAN] is held at center point. (a) cumulative $\mathrm{CH}_{4}$ production and (b) acetate degradation rate. methanogenesis of volatile fatty acids (VFAs), and further increase of [Mag] did not improve the reaction rate.

The optimized condition of [TAN] for both responses was at $1.5 \mathrm{~g} / \mathrm{L}$, which is accepted to be non-inhibitory [13]. TAN has no adverse effect on methanogenic consortia when it accumulates up to $1.5 \mathrm{~g} / \mathrm{L}$. Above this level, intolerable free $\mathrm{NH}_{3}$ nitrogen concentration ([FAN]) may accumulate in the digester and inhibit methanogenesis [15].

[TAN] significantly affected $\mathrm{CH}_{4}$ production and acetate degradation rate (Table 3). From the equilibrium equation of [TAN] and [FAN] [32], the calculated [FAN] supplied in this study were 59, 157, and $256 \mathrm{mg} / \mathrm{L}$, which correspond to 1.5, 4.0, and 6.5 g/L TAN, respectively. The inhibition effect of TAN is caused by the diffusion of free $\mathrm{NH}_{3}$ (FA) through the membrane cell; thus, cells must increase the energy invested to maintain intercellular pH. Eventually, the expression of several key enzymes that contribute to substrate degradation and product formation will be disrupted [15, 33]. For methanogens, FAN substantially suppresses the expression of coenzyme F420, which is a key coenzyme for $\mathrm{CH}_{4}$ production, up to $97 \%$ after exposure with 254 mg-FAN/L for $50 \mathrm{~d}$ [34]. These results explained the significant effect of [TAN] on both responses and the low cumulative $\mathrm{CH}_{4}$ production and acetate degradation rate when the reactors were supplied with $6.5 \mathrm{~g}$-TAN/L.

\subsection{Interaction between Independent Variables}

The signs of the coefficients indicate promotion or inhibition of each independent variable on the response functions [27]. Eq. (3) and (4) both indicate that $Y_{1}$ and $Y_{2}$ are negatively correlated with $V_{\mathrm{CAT}}$ and [TAN] but positively correlated with [Mag]. These indicate that the more negative $V_{\mathrm{CAT}}$ and the higher [TAN] inhibit cumulative $\mathrm{CH}_{4}$ production and acetate degradation rate, whereas the increase in [Mag] promotes both responses.

$V_{\mathrm{CAT}}$ and [TAN] showed significant interaction $(p<0.05)$ on $Y_{1}$ and $Y_{2}$. $V_{\text {CAT }}$ supplied to the system provides electromotive force for $\mathrm{NH}_{3}$ removal: ammonium ions that react with hydroxides in the system are converted to $\mathrm{NH}_{3}$, which then escape into the headspace of the reactor. This is the alleviative effect of EM in $\mathrm{NH}_{3}$ inhibition conditions during $\mathrm{AD}$ [35] that also explained the interaction between $V_{\mathrm{CAT}}$ and [TAN] on both responses.

In contrast, [Mag] did not interact significantly with either $V_{\mathrm{CAT}}$ or [TAN] $(p>0.05)$. This result indicates that [Mag] had less effect than other independent variables. Mag has been reported responsible for reactor stability operated over $600 \mathrm{~d}$ [36]. Therefore, Mag supplementation showed insignificant effect on two responses for linear, quadratic, and interaction terms due to short-term operation. This also indicates that $V_{\mathrm{CAT}}$ alone is sufficient to promote reaction rate through DIET during short-term operation.

Regardless of the insignificant effect of [Mag] in linear and interaction terms, Mag alleviates $\mathrm{NH}_{3}$ stress in $\mathrm{AD}$ indirectly. Microbial cells require more energy for cell maintenance to survive in high $\left[\mathrm{NH}_{3}\right]$ that potentially inhibits other enzymatic reactions involved in methanogenesis [15]. A high electron-transfer efficiency mediated by Mag alleviates the problem of energy deficiency caused by $\mathrm{NH}_{3}$ inhibition [9]. 


\subsection{Effect of $\mathrm{V}_{\mathrm{CAT}}$, [Mag], and [TAN] on Microbial Populations}

PCA was performed on total bacterial and archaeal populations to investigate how microbial populations were affected by independent variables employed in this study (Fig. 3). The bacterial and archaeal populations were positively correlated $(r=0.63, p$ $<0.05$ ), and first two principal components (PC-1 and PC-2) correspond to $83.1 \%$ of the total variation between microbial populations. The microbial populations clustered based on $V_{\text {CAT }}$ regardless of [Mag] and [TAN] supplied to the systems. To confirm the significant difference between those clusters, ANOSIM was performed with Euclidean distance and 9,999 permutations. The ANOSIM R-value of the test was 0.611 ( $p<0.01$ ), indicates that microbial growth varied significantly in response to $V_{\text {CAT }}$.

Violin-boxplots (Fig. S1) visualize $V_{\text {CAT }}$ influence on total bacterial and archaeal populations. At the beginning of the experiment, average populations were $1.19 \times 10^{9}\left( \pm 2.24 \times 10^{8}\right)$ copies $/ \mathrm{mL}$ for total bacteria and $1.29 \times 10^{7}\left( \pm 1.61 \times 10^{6}\right)$ copies $/ \mathrm{mL}$ for total archaea.

The effect of $V_{\mathrm{CAT}}$ on microbial populations varied according to its magnitude. At the end of experiment, $V_{\mathrm{CAT}}=-600 \mathrm{mV}$ contributed to significant increase $(p<0.01)$ of microbial populations with average total bacteria and archaea were $1.32 \times 10^{9}( \pm 4.16$ $\left.\times 10^{8}\right)$ copies $/ \mathrm{mL}$ and $1.47 \times 10^{7}\left( \pm 1.07 \times 10^{6}\right)$ copies $/ \mathrm{mL}$, respectively. The supplies of different [Mag] and [TAN] led to a wide distribution of bacterial populations. In contrast, reactors that were subjected to $V_{\mathrm{CAT}}=-800$ and $-1,000 \mathrm{mV}$, the different [Mag] and [TAN] supplied to the system had comparatively little effect on microbial concentration, which is indicated by its narrow distribution. $V_{\text {CAT }}=-800 \mathrm{mV}$ significantly increased $(p<0.01)$ total microbial concentration to almost double at the endpoint of experiment, with $2.10 \times 10^{9}\left( \pm 7.29 \times 10^{7}\right)$ copies $/ \mathrm{mL}$ of bacterial

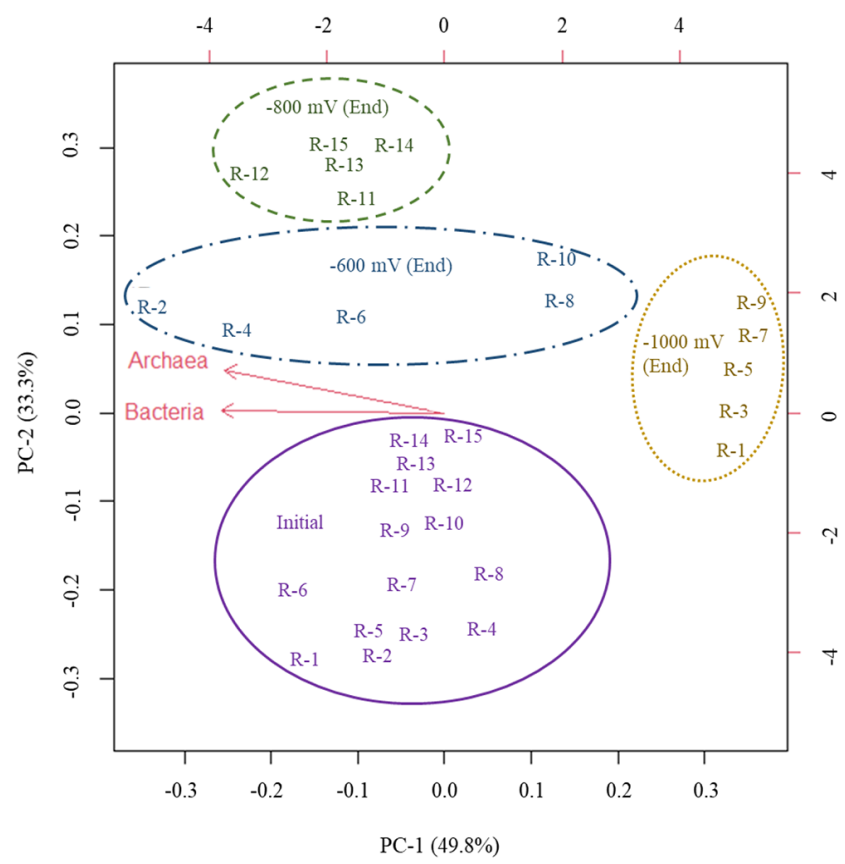

Fig. 3. Principal component analysis of total bacterial and archaeal populations at the beginning and end of experiment. and $2.04 \times 10^{7}\left( \pm 1.71 \times 10^{6}\right)$ copies $/ \mathrm{mL}$ of archaeal concentrations. Whereas $V_{\mathrm{CAT}}=-1,000 \mathrm{mV}$ caused significant decrease $(p<0.01)$ of microbial population with $(4.28 \pm 1.68) \times 10^{7}$ copies $/ \mathrm{mL}$ and $1.38 \times 10^{6}\left( \pm 5.79 \times 10^{5}\right)$ copies $/ \mathrm{mL}$ of bacterial and archaeal concentrations, respectively.

Appropriate $V_{\mathrm{CAT}}$ may increase the abundance of several functional features, such as biogenesis of cell wall/membrane/envelope, coenzyme transport and metabolism, and citrate cycle metabolic pathway [35]. These functional features are responsible for the improvement of extracellular electron transfer that is involved in methanogenesis. This relationship explains the increase of microbial concentrations in reactors that had been subjected to $V_{\mathrm{CAT}}$ $=-800 \mathrm{mV}$, which led to high cumulative $\mathrm{CH}_{4}$ production and high acetate degradation rate (Fig. 2).

In this study, electrochemical $\mathrm{NH}_{3}$ removal was only observed in reactors to which $V_{\mathrm{CAT}}=-1,000 \mathrm{mV}$ ([TAN] decreased 73.7 $\pm 5.5 \%$ ) or $-800 \mathrm{mV}$ ([TAN] decreased $6.2 \pm 1.1 \%$ ) had been applied. This observation also aligns with previous study [27] that reported up to $70.6 \%$ decreased [TAN] in their EM system. Increasing negativity of $V_{\text {CAT }}$ could trigger rupture of cell wall and cause irreversible damage to cell membranes [37]; this response explains the decrease of microbial concentrations at $V_{\mathrm{CAT}}=-1,000 \mathrm{mV}$ (Fig. S1), regardless of the alleviative effect of strong $V_{\mathrm{CAT}}$ in reducing [TAN]. Furthermore, decreasing microbial concentrations caused low cumulative $\mathrm{CH}_{4}$ production and acetate degradation rate (Fig. 2).

The final product of acetate degradation in this study was $\mathrm{CH}_{4}$. The acetate-removal efficiency of all reactors reached 100\% after different elapsed times because it affected by independent variables supplied to the system. Regardless of [Mag], cumulative $\mathrm{CH}_{4}$ production at $V_{\text {CAT }}=-600 \mathrm{mV}$ and $-800 \mathrm{mV}$ with $[\mathrm{TAN}]=1.5 \mathrm{~g} / \mathrm{L}$ and $4.0 \mathrm{~g} / \mathrm{L}$ ranged from $78.8-118.0 \%$ of theoretical value. Cumulative $\mathrm{CH}_{4}$ production $>100 \%$ of theoretical value in EM system has been reported previously [7]. Considering some fraction of substrate is utilized by microorganisms for cell synthesis and maintenance [38], the result indicated that acetate was mainly utilized for $\mathrm{CH}_{4}$ production. In contrast, $\mathrm{CH}_{4}$ production at $V_{\mathrm{CAT}}$ $=-1,000 \mathrm{mV}$ with $6.5 \mathrm{~g}$-TAN/L ranged from $6.4-40.3 \%$ of the theoretical value. The acetate removal efficiency also reached $100 \%$ in this system, despite the low $\mathrm{CH}_{4}$ production. The results indicate that the acetate was mainly used for cell maintenance to survive in $\mathrm{NH}_{3}$ stress conditions.

Methanogen populations were also quantified to identify the dominant methanogens (Fig. 4). Of three orders (Methanococcales, Methanobacteriales, and Methanomicrobiales) and two families (Methanosarcinacea and Methanosaetacea) that commonly occur in anaerobic digesters, only Methanosaetacea, Methanomicrobiales and Methanobacteriales were detected. As shown in Fig. 4, $V_{\mathrm{CAT}}$ shifted methanogenesis pathway from acetoclastic to hydrogenotrophic. It was indicated by the decrease of Methanosaetaceae concentration and increase of Methanomicrobiales and Methanobacteriales at end of experiment.

Although microbial populations were mainly affected by $V_{\mathrm{CAT}}$ in this study, [Mag] and [TAN] also affected them to some degree. Mag affects methanogens growth and its activities [12, 39-41]. Population of hydrogenotrophic methanogens (HMs), especially Methanobacteriales increased by $>12$-times in $376 \mathrm{~d}$. Mag stimulated the growth of methanogens through syntrophic VFA-oxidizing 

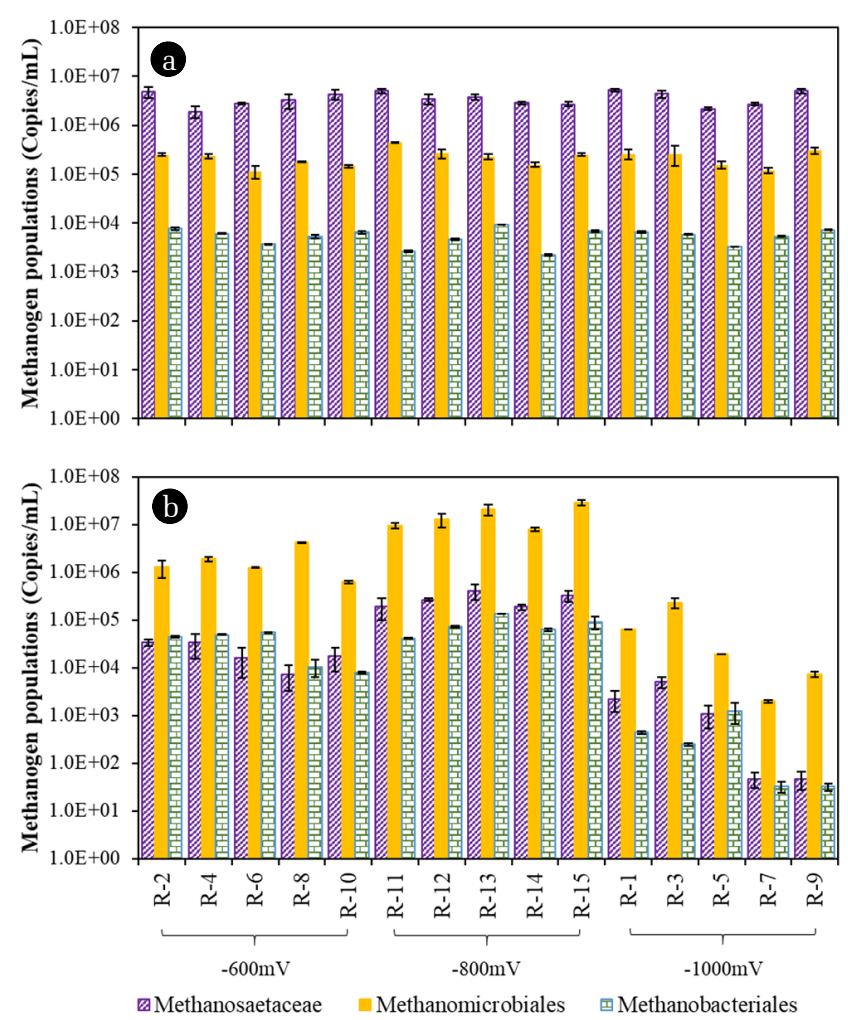

Fig. 4. Methanogen populations at the (a) beginning and (b) end of experiment.

bacteria via DIET [12]. Furthermore, Mag supplementation enhanced methanogenesis by increasing the expression of coenzyme F420 and coenzyme M by up to 1.8 and 1.7-times, respectively. Relative abundance of Methanolinea, which belongs to Methanobacteriales, increased up to $62.6 \%$. Excitation emission matrix fluorescence spectroscopy also showed significant increase of soluble microbial products (SMPs) in semi-continuous AD supplemented with Mag for $20 \mathrm{~d}$ [39]. SMPs are organic compounds released during normal microbial metabolism; they indicate the activity of $\mathrm{AD}$ systems [40]. Another study reported the increase of mcrA gene copy numbers up to 4.3-times in batch $\mathrm{AD}$ after supplemented with Mag for $29 \mathrm{~d}$ [41].

[TAN] from 1.7 to $14.0 \mathrm{~g} / \mathrm{L}$ has been reported to reduce methanogenesis by $50 \%$. The wide range of [TAN] inhibition influenced by operational conditions ( $\mathrm{pH}$, temperature, HRT), substrate conditions, and inoculum acclimatization [13, 14]. TAN affects the growth and activities of methanogens and the growth of syntrophic VFA-oxidizing bacteria, although the inhibition effects are less severe than methanogens. Therefore, $\mathrm{AD}$ system suffering from $\mathrm{NH}_{3}$ inhibition will also suffer from VFA accumulation [15].

HMs have better tolerance than acetoclastic methanogens to high $\mathrm{NH}_{3}$ levels [13, 14, 42, 43]. HMs can maintain homeostatic system by activating $\mathrm{K}^{+}$or $\mathrm{Na}^{+} / \mathrm{H}^{+}$antiporter and $\mathrm{K}^{+}$uptake systems to regulate turgor pressure and maintain cytoplasmic $\mathrm{pH}$ as a response to $\mathrm{NH}_{3}$ protonation. Concurrent translocation of $\mathrm{Na}^{+} / \mathrm{H}^{+}$ across the membrane leads to proton gradient generation that is required to synthesize adenosine triphosphate. Therefore, HMs can conserve energy in $\mathrm{NH}_{3}$ stressed conditions [44]. This ability may explain the increase of HMs population in this study.

This study provides valuable information to guide optimization of an EM process coupled with Mag addition in the presence of $\mathrm{NH}_{3}$. Nevertheless, this study was conducted in batch system. Further experiments should consider process optimization of similar independent variables in continuous system that uses complex substrates.

\section{Conclusions}

The interactions of $V_{\mathrm{CAT}}$ and [Mag] on cumulative methane production and acetate degradation rate in EM system at different $\mathrm{NH}_{3}$ conditions were quantified using a response-surface model. The optimal responses that enhanced cumulative $\mathrm{CH}_{4}$ production were achieved at $V_{\mathrm{CAT}}=-757.6 \mathrm{mV}$, [Mag] $=18.2 \mathrm{mM}$, and [TAN] $=1.5 \mathrm{~g}$-TAN/L. The optimal responses that enhanced acetate degradation rate were achieved at $V_{\mathrm{CAT}}=-737.4 \mathrm{mV}$, [Mag] $=21.4$ $\mathrm{mM}$, and $[\mathrm{TAN}]=1.5 \mathrm{~g}$-TAN/L. $V_{\mathrm{CAT}}$ applied to the system promoted microbial growth (at $V_{\mathrm{CAT}}=-800 \mathrm{mV}$ ) or electrochemical $\mathrm{NH}_{3}$ removal (at $V_{\mathrm{CAT}}=-1,000 \mathrm{mV}$ ). $V_{\mathrm{CAT}}$ application also caused a shift in methanogenesis pathway from methanogenic to hydrogenotrophic.

\section{Acknowledgments}

This research supported by Biogasification of Proteo-lipid rich biomass for 70\% bioenergy recovery efficiency with neural-network based smart micro-biogas system of KETEP Grant, funded by MOTIE Republic of Korea (No.20183010092790).

\section{Author Contributions}

A.Y (Ph. D. student) conducted the experiment, wrote the manuscript, analyzed and interpreted the data. J.L (Assistant Professor) prepared experimental design. S.H.P (Ph. D. student) investigated literature and revised the manuscript. S.H (Professor) supervised the research, funding acquisition, and revised the manuscript.

\section{References}

1. Baek G, Kim J, Kim J, Lee C. Role and Potential of Direct Interspecies Electron Transfer in Anaerobic Digestion. Energies 2018;11(1):107.

2. Fu Q, Wang DB, Li XM, et al. Towards hydrogen production from waste activated sludge: Principles, challenges and perspectives. Renew. Sust. Energ. Rev. 2021;135:110283.

3. Cheng QW, Call DF. Hardwiring microbes via direct interspecies electron transfer: mechanisms and applications. Environ. Sci. Process. Impacts. 2016;18(8):968-980.

4. Blasco-Gomez R, Batlle-Vilanova P, Villano M, Balaguer MD, Colprim J, Puig S. On the Edge of Research and Technological 
Application: A Critical Review of Electromethanogenesis. Int. J. Mol. Sci. 2017;18(4):874.

5. Lee B, Park JG, Shin WB, Tian DJ, Jun HB. Microbial communities change in an anaerobic digestion after application of microbial electrolysis cells. Bioresour. Technol. 2017;234:273-280.

6. Flores-Rodriguez C, Reddy CN, Min B. Enhanced methane production from acetate intermediate by bioelectrochemical anaerobic digestion at optimal applied voltages. Biomass Bioenerg. 2019;127:105261.

7. Bo T, Zhu XY, Zhang LX, et al. A new upgraded biogas production process: Coupling microbial electrolysis cell and anaerobic digestion in single-chamber, barrel-shape stainless steel reactor. Electrochem. Commun. 2014;45:67-70.

8. Cruz Viggi C, Rossetti S, Fazi S, Paiano P, Majone M, Aulenta F. Magnetite particles triggering a faster and more robust syntrophic pathway of methanogenic propionate degradation. Environ. Sci. Technol. 2014;48(13):7536-7543.

9. Lee J, Koo T, Yulisa A, Hwang S. Magnetite as an enhancer in methanogenic degradation of volatile fatty acids under ammonia-stressed condition. J. Environ. Manage. 2019;241:418-426.

10. Liu PP, Liang P, Jiang Y, et al. Stimulated electron transfer inside electroactive biofilm by magnetite for increased performance microbial fuel cell. Appl. Energy 2018;216:382-388.

11. Baek G, Jung H, Kim J, Lee C. A long-term study on the effect of magnetite supplementation in continuous anaerobic digestion of dairy effluent - Magnetic separation and recycling of magnetite. Bioresour. Technol. 2017;241:830-840.

12. Baek G, Kim J, Lee C. A long-term study on the effect of magnetite supplementation in continuous anaerobic digestion of dairy effluent - Enhancement in process performance and stability. Bioresour. Technol. 2016;222:344-354.

13. Yenigun O, Demirel B. Ammonia inhibition in anaerobic digestion: A review. Process Biochem. 2013;48(5-6):901-911.

14. Chen Y, Cheng JJ, Creamer KS. Inhibition of anaerobic digestion process: a review. Bioresour. Technol. 2008;99(10):4044-4064.

15. Liu Y, Ngo HH, Guo W, Peng L, Wang D, Ni B. The roles of free ammonia (FA) in biological wastewater treatment processes: A review. Environ. Int. 2019;123:10-19.

16. Pan XF, Zhao LX, Li CX, et al. Deep insights into the network of acetate metabolism in anaerobic digestion: focusing on syntrophic acetate oxidation and homoacetogenesis. Water Res. 2021;190:116774.

17. Angelidaki I, Alves M, Bolzonella D, et al. Defining the biomethane potential (BMP) of solid organic wastes and energy crops: a proposed protocol for batch assays. Water Sci. Technol. 2009;59(5):927-934.

18. Call DF, Logan BE. A method for high throughput bioelectrochemical research based on small scale microbial electrolysis cells. Biosens. Bioelectron. 2011;26(11):4526-4531.

19. Bezerra MA, Santelli RE, Oliveira EP, Villar LS, Escaleira LA. Response surface methodology (RSM) as a tool for optimization in analytical chemistry. Talanta 2008;76(5):965-977.

20. Rosenbaum M, Aulenta F, Villano M, Angenent LT. Cathodes as electron donors for microbial metabolism: which extracellular electron transfer mechanisms are involved? Bioresour. Technol. 2011;102(1):324-333.

21. Dykstra CM, Pavlostathis SG. Methanogenic Biocathode
Microbial Community Development and the Role of Bacteria. Environ. Sci. Technol. 2017;51(9):5306-5316.

22. Spinner NS, Vega JA, Mustain WE. Recent progress in the electrochemical conversion and utilization of $\mathrm{CO}_{2}$. Catal. Sci. Technol. 2012;2(1):19-28.

23. Yang ZM, Guo RB, Shi XS, Wang CS, Wang L, Dai M. Magnetite nanoparticles enable a rapid conversion of volatile fatty acids to methane. Rsc Adv. 2016;6(31):25662-25668.

24. Lee J, Kim E, Han G, Tongco JV, Shin SG, Hwang S. Microbial communities underpinning mesophilic anaerobic digesters treating food wastewater or sewage sludge: A full-scale study. Bioresour. Technol. 2018;259:388-397.

25. Yu Y, Lee C, Kim J, Hwang S. Group-specific primer and probe sets to detect methanogenic communities using quantitative real-time polymerase chain reaction. Biotechnol. Bioeng. 2005;89(6):670-679.

26. APHA-AWWA-WEF. Standard Methods for the Examination of Water and Wastewater 23rd Edition. 23rd ed. Washington, DC: American Public Health Association; 2017.

27. Song Q, Li M, Wang L, Ma X, Liu F, Liu X. Mechanism and optimization of electrochemical system for simultaneous removal of nitrate and ammonia. J. Hazard. Mater. 2019;363: 119-126.

28. Rozendal RA, Hamelers HV, Rabaey K, Keller J, Buisman CJ. Towards practical implementation of bioelectrochemical wastewater treatment. Trends Biotechnol. 2008;26(8):450-459.

29. Baek G, Kim J, Lee S, Lee C. Development of biocathode during repeated cycles of bioelectrochemical conversion of carbon dioxide to methane. Bioresour. Technol. 2017;241:1201-1207.

30. Katuri KP, Kalathil S, Ragab A, et al. Dual-Function Electrocatalytic and Macroporous Hollow-Fiber Cathode for Converting Waste Streams to Valuable Resources Using Microbial Electrochemical Systems. Adv. Mater. 2018;30(26): 1707072.

31. Ragab A, Shaw DR, Katuri KP, Saikaly PE. Effects of set cathode potentials on microbial electrosynthesis system performance and biocathode methanogen function at a metatranscriptional level. Sci. Rep. 2020;10(1):19824.

32. Fotidis IA, Karakashev D, Kotsopoulos TA, Martzopoulos GG, Angelidaki I. Effect of ammonium and acetate on methanogenic pathway and methanogenic community composition. FEMS Microbiol. Ecol. 2013;83(1):38-48.

33. Zhao JW, Liu YW, Wang YL, et al. Clarifying the Role of Free Ammonia in the Production of Short-Chain Fatty Acids from Waste Activated Sludge Anaerobic Fermentation. Acs Sustain. Chem. Eng. 2018;6(11):14104-14113.

34. Wang D, Duan Y, Yang Q, et al. Free ammonia enhances dark fermentative hydrogen production from waste activated sludge. Water Res. 2018;133:272-281.

35. Wang H, Zheng X, Yan Q, Zhang G, Kim JR. Microbial community and metabolic responses to electrical field intensity for alleviation of ammonia inhibition in an integrated bioelectrochemical system (BES). Bioresour. Technol. 2021;336:125332.

36. Baek G, Kim J, Kim J, Lee C. Individual and combined effects of magnetite addition and external voltage application on anaerobic digestion of dairy wastewater. Bioresour. Technol. 2020;297:122443. 
37. Ding A, Yang Y, Sun GD, Wu DL. Impact of applied voltage on methane generation and microbial activities in an anaerobic microbial electrolysis cell (MEC). Chem. Eng. J. 2016;283:260-265.

38. Gerardi MH. The Microbiology of Anaerobic Digesters. New Jersey: John Wiley \& Sons, Inc.; 2003.

39. Zhong D, Li JX, Ma WC, Qian FY. Clarifying the synergetic effect of magnetite nanoparticles in the methane production process. Environ. Sci. Pollut. Res. 2020;27(14):17054-17062.

40. Ni BJ, Rittmann BE, Yu HQ. Soluble microbial products and their implications in mixed culture biotechnology. Trends Biotechnol. 2011;29(9):454-463.

41. Zhou SG, Xu JL, Yang GQ, Zhuang L. Methanogenesis affected by the co-occurrence of iron(III) oxides and humic substances. FEMS Microbiol. Ecol. 2014;88(1):107-120.

42. Angelidaki I, Ahring BK. Thermophilic Anaerobic-Digestion of Livestock Waste - the Effect of Ammonia. Appl. Microbiol. Biotechnol. 1993;38(4):560-564.

43. Poirier S, Desmond-Le Quemener E, Madigou C, Bouchez T, Chapleur O. Anaerobic digestion of biowaste under extreme ammonia concentration: Identification of key microbial phylotypes. Bioresour. Technol. 2016;207:92-101.

44. Yan M, Treu L, Zhu XY, et al. Insights into Ammonia Adaptation and Methanogenic Precursor Oxidation by Genome-Centric Analysis. Environ. Sci. Technol. 2020;54(19):12568-12582. 